\title{
A practical method in measurement of perforation size during cartilage tympanoplasty
}

\author{
Kemal Keseroğlu๑, Sibel Alicura Tokgöz $\odot$, Elif Kaya Çelik $\odot$, İstemihan Akın๑, Ali Özdek® \\ Department of Otorhinolaryngology, University of Health Sciences, Dışkapı Yıldırım Beyazıt Training and Research Hospital, Ankara, \\ Turkey
}

\begin{abstract}
Cartilage has been used in otologic surgery for ossicular reconstruction and grafting since 1960s. Due to low metabolic rate, stiffness and stability properties with regard to fascia, it is thought to be more effective in tympanoplasty. With the help of this measurement technique, redundant oversized harvesting of cartilage can be prevented and overmanuplation during graft replacement especially after a delicate ossiculoplasty procedure can be avoided. The aim of this study was to demonstrate the preparation of optimal island cartilage composite graft with a simple sterile suture package template for the appropriate size of the tympanic membrane perforation, and to provide a functional surgery with minimal donor site defect and minimal manipulation. With this technique, 143 patients with chronic otitis have been operated in our clinic. No complications with respect to this method, have been observed up to date. Using an easily prepared template is a simple and effective method for measuring the perforation size.
\end{abstract}

Keywords: Cartilage, tympanoplasty, perforation size measurement, endoscopic cartilage tympanoplasty, butterfly inlay myringoplasty

C artilage usage as a graft in tympanoplasty has become more popular after the first attempt by Salen since 1963 [1]. Tragal and conchal cartilage are the preferred donor sites due to easy of access in the surgical field [2]. Different types of cartilage modifications were tried and Tos [1] proposed a classification of cartilage tympanoplasty methods which was classified in 7 groups (Group A to F).

Composite island, shield and butterfly cartilage grafts are the commonly used graft types especially in pars tensa perforations [3, 4]. Due to individual anatomic variations of annular ring size, tympanomeatal angle and perforation shape, localization; surgeon may have some trouble to predict the optimum size of the cartilage graft. A trial of improper, oversized graft replacement especially after a delicate ossiculoplasty may result in over manuplation which can result in distruption of ossiculoplasty and prolongation of the surgery. Moreover, insufficient cartilage graft may lead to dehissence between perforation edge and perforation margin [2].

The aim of this study was to demonstrate the preparation of optimal island cartilage composite graft and butterfly graft with a simple template for the appropriate size of the tympanic membrane perforation, and to provide a functional surgery with minimal donor site defect and minimal manipulation.

\section{TECHNIQUE}

A sterile suture package was cut and prepared as 
template (Fig. 1). Before the elevation of tympanomeatal flap, the size of the perforation after refreshment of the perforation edges was confirmed whether it was adequate or not, by fitting the paper template over the perforation site. After the determination of optimum size of island cartilage graft, harvesting of the tragal cartilage was performed according to measured size of template. Before the end of surgery, after performing the ossiculoplasty, optimum closure of perforation was rechecked with the template after reposition of tympanomeatal flap. Finally, closure of the tympanic membrane was completed with this preformed cartilage graft. This technique was used in 143 tympanoplasty surgeries with endoscopic and microscopic approaches and no complications such as chorda tympani, ossicular chain or tympanomeatal flap damage with respect to this method have been observed up to date. (Figs. 2, 3 and 4).

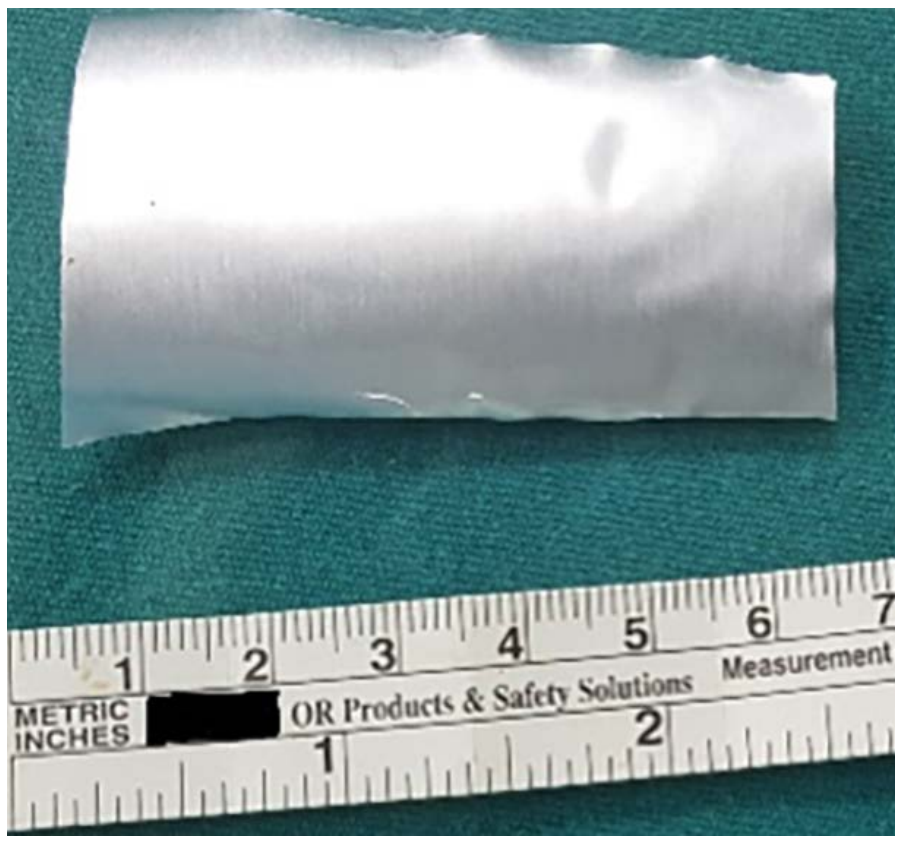

Fig. 1. Sterile suture paper
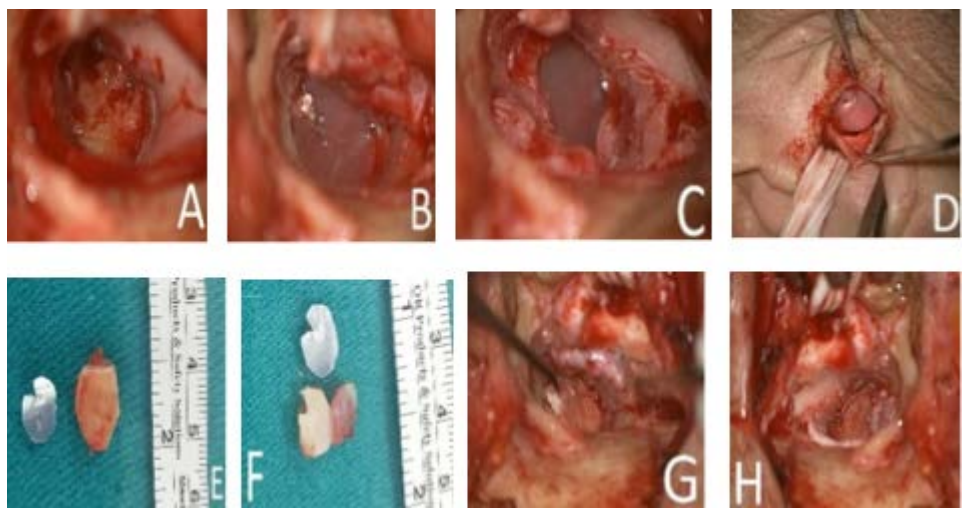

Fig. 2. Suture paper template technique in microscopic tympanoplasty. (A) Microscopic view of perforation after refreshment of the edges, (B) Suture paper template demo after tympanomeatal flap elevation, (C) Template fitting after reposition of tympanomeatal flap, (D) Harvest of tragal cartilage according to template, (E, F) Cartilage graft shaping, (G) Cartilage graft replacement before tympanomeatal flap reposition, and $(\mathrm{H})$ Cartilage graft replacement after tympanomeatal flap reposition.

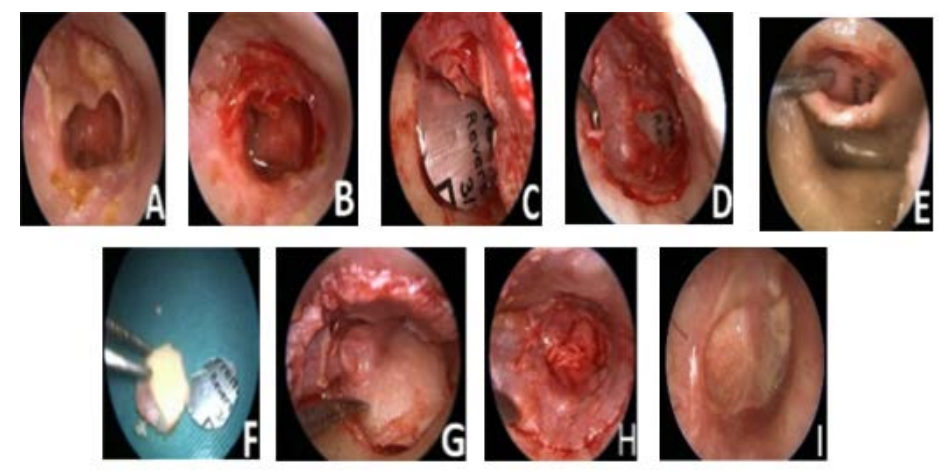

Fig. 3. Suture paper template technique in endoscopic transcanal tympanoplasty. (A) Endoscopic view of perforation, (B) After refreshment of perforation edges, (C) Suture paper template demo after tympanomeatal flap elevation, (D) Template fitting after reposition of tympanomeatal flap, (E) Harvest of tragal cartilage according to template, (F) Cartilage graft shaping, (G, H) Cartilage grafting after tympanmeatal flap reposition, and (I) Postoperative 6. month view of tympanic membrane. 


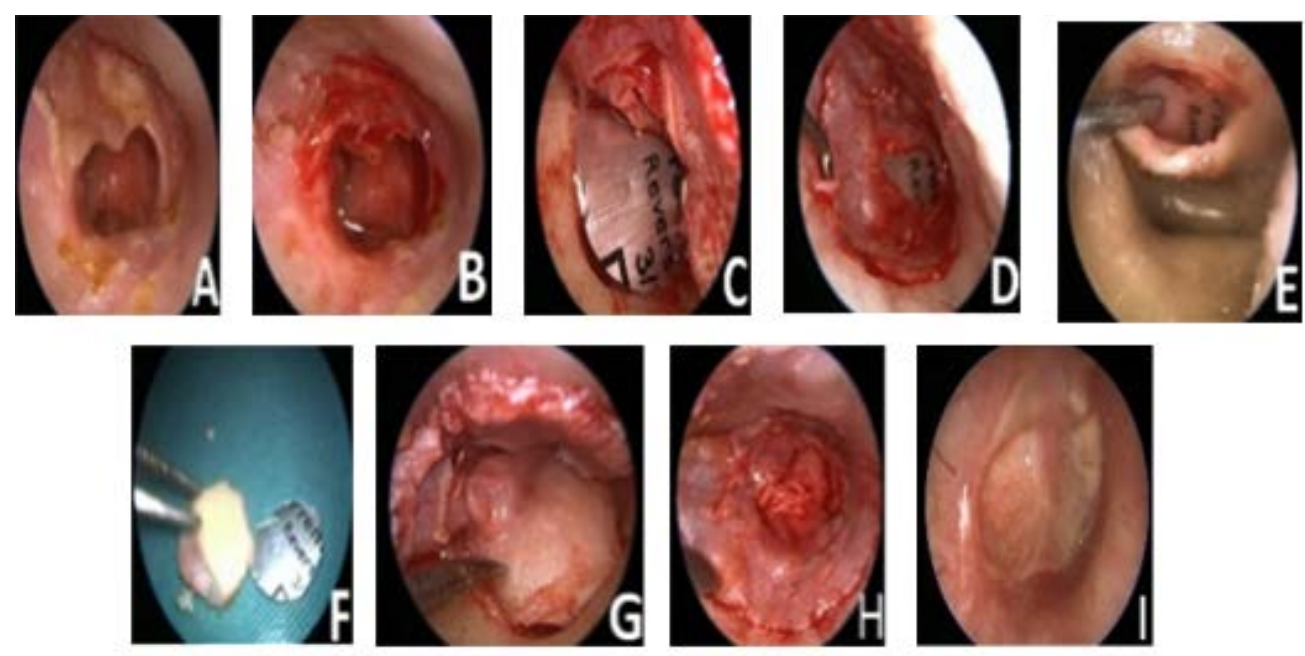

Fig. 3. Suture paper template technique in endoscopic transcanal tympanoplasty. (A) Endoscopic view of perforation, (B) After refreshment of perforation edges, (C) Suture paper template demo after tympanomeatal flap elevation, (D) Template fitting after reposition of tympanomeatal flap, (E) Harvest of tragal cartilage according to template, (F) Cartilage graft shaping, (G, H) Cartilage grafting after tympanmeatal flap reposition, and (I) Postoperative 6. month view of tympanic membrane.

\section{DISCUSSION}

Cartilage has been used in otologic surgery for ossicular reconstruction and grafting since 1960s. Due to low resorption rate, stiffness and stability properties with regard to fascia, it is thought to be more effective in patients especially with higher risk of reperforation. There is a still debate about the thickness of the cartilage which influences the hearing outcome [5]. However, to get hearing success, anatomic closure of perforation must be obtained firstly. Thus, optimum size and shape of cartilage graft with proper replacement is needed. Seta et al. used auricular speculum to evaluate the required graft size to reduce the surgical time during cartilage tympanoplasty [6]. Also Eren et al. [7] introduced a device called 'otologic compass' to measure the perforation size during inlay butterfly myringoplasty. They concluded that this device decreased the number of cartilage shaping attempts and operation time. By the help of this template technique exact fitting of graft can be demonstrated especially at the anterior border of the perforation and optimum relationship of graft with bony annulus can be achieved. At the donor site of graft, this template provides sufficient amount of cartilage harvest, preventing excessive cartilage loss which can result in better cosmetic outcome. Moreover, there is no need for any extra device thus, using a suture paper is cost effective.

\section{CONCLUSION}

Using an easily prepared template is a simple and effective method for measuring the perforation size. With this method, sufficient harvesting can be achieved and overmanuplation of graft during placement can be avoided which can shorten the duration of the surgery.

\section{Conflict of interest}

The authors disclosed no conflict of interest during the preparation or publication of this manuscript.

\section{Financing}

The authors disclosed that they did not receive any grant during conduction or writing of this study.

\section{REFERENCES}

1. Tos M. Cartilage tympanoplasty methods: proposal of a classification. Otolaryngol Head Neck Surg 2008;139:747-58.

2. Yung M. Cartilage tympanoplasty: literature review. J Laryngol Otol 2008;122:663-72.

3. Cavaliere M, Panetti M, Iemma M. Tragal cartilage shield tympanoplasty: our technique and results in 612 cases. Acta Otolaryngol 2014;134:890-7.

4. Ghanem MA, Monroy A, Alizade FS, Nicolau Y, Eavey RD. Butterfly cartilage graft inlay tympanoplasty for large perforations. Laryngoscope 2006;116:1813-6.

5. Jalali MM, Motasaddi M, Kouhi A, Dabiri S, Soleimani R. 
Comparison of cartilage with temporalis fascia tympanoplasty: A meta-analysis of comparative studies. Laryngoscope 2017; 127:2139-48.

6. De Seta E, Covelli E, De Seta D, Mancini P, Filipo R. Cartilage tympanoplasty: how to reduce surgery time. J Laryngol Otol
2010;124:784-5.

7. Eren SB, Tugrul S, Ozucer B, Dogan R, Ozturan O. A randomized prospective trial of a novel device for measuring perforation size during inlay 'butterfly' myringoplasty. Am J Otolaryngol 2014;35:305-8 